European

Thyroid Journal
Eur Thyroid J 2018;7:21-26

DOI: $10.1159 / 000481857$
Received: June 12, 2017

Accepted after revision: September 26, 2017

Published online: November 27, 2017

\title{
Ultrasound Measurements of Thyroid Gland Volume at 36 Weeks' Corrected Gestational Age in Extremely Preterm Infants Born before 28 Weeks' Gestation
}

\author{
Sze May Nga, $\quad$ Mark A. Turner ${ }^{a}$ Shivaram Avula ${ }^{c}$ \\ aDepartment of Women's and Children's Health, Institute of Translational Medicine, University of Liverpool, \\ Liverpool, UK; ${ }^{b}$ Department of Paediatrics, Southport and Ormskirk NHS Trust, Ormskirk, UK; ' ${ }^{\circ}$ Department of \\ Radiology, Alder Hey Foundation Trust Hospital, Liverpool, UK
}

\section{Keywords}

Thyroid $\cdot$ Ultrasound $\cdot$ Preterm infants

\begin{abstract}
Background: Thyroid ultrasound is a non-invasive imaging tool and provides good evaluation of thyroid anatomy, location, vascularisation, and echogenicity. The aim of this study was to assess thyroid function and thyroid volume in extremely preterm infants born before 28 weeks' gestation evaluated at 36 weeks' corrected gestational age (CGA) compared to term infants' normative data in the literature. Design: In this largest prospective UK study of extremely premature infants born at less than 28 weeks' gestation, thyroid volume measurement was assessed at 36 weeks' CGA. Fiftyfive extremely preterm infants ( 28 males) who were born before 28 weeks' gestation were recruited to the study. All infants had ultrasound assessment of the thyroid gland at 36 weeks' CGA. We also prospectively measured thyroid stimulating hormone (TSH) and free thyroxine $\left(\mathrm{FT}_{4}\right)$ in all infants at the time of recruitment (within 5 days of birth), at days 14, 21, and 28, and at 36 weeks' CGA. Results: The mean thyroid volume was measured at $0.57 \mathrm{~mL}(\mathrm{SD} \pm 0.18$ ). There was no association between mean thyroid volume and thyroid func-
\end{abstract}

tion ( $\mathrm{TSH}$ or $\mathrm{FT}_{4}$ ). No associations were found between mean thyroid volume and gestation or birth weight in these infants. Conclusions: Our findings provide a reference range with a mean thyroid volume of $0.57 \mathrm{~mL}(S D \pm 0.18)$ in this extremely preterm age group if less than 28 weeks' gestation. Thyroid volume at birth can vary from country to country due to variations in iodine intake as well as gestational age.

(c) 2017 European Thyroid Association Published by S. Karger AG, Basel

\section{Introduction}

Neonatal thyroid ultrasonography has an important role in assessing thyroid anatomy in newborns with thyroid dysfunction. Hypothyroxinaemia of prematurity is also commonly reported among infants born prematurely and this is associated with an increased risk of disability [1-3]. Factors that may contribute to abnormal thyroid function in preterm infants include immaturity of the thyroid gland, disruption of maternal transfer of thyroid hormones through the placenta, and interaction with other enzyme systems [4]. The size of the thyroid gland is closely regulated during foetal development [5].

Dr. Sze May Ng, MBBS (Hons), FHEA, FRCPCH, MSc, LLM, PhD 
Table 1. Demographics and baseline characteristics $(N=55)$

\begin{tabular}{ll}
\hline Males, $n$ & 28 \\
Birth weight, g & $893.8(178.1)$ \\
Gestational age, weeks & $26.2(1.2)$ \\
CRIB score & $5.37(3.53)$ \\
Twin births (pairs), $n$ & 8 \\
Maternal age, years & $28.26(7.34)$ \\
Maternal history of smoking during & \\
$\quad$ pregnancy & 24 \\
Maternal history of alcohol during & \\
$\quad$ pregnancy & 5.2 \\
Maternal FT, pmol/L & $15.92(3.03)$ \\
Antenatal steroid therapy & 92.6 \\
Delivery by caesarean section & 33 \\
\hline
\end{tabular}

Data are expressed as mean (SD) for continuous outcomes and $\%$ for categorical outcomes. CRIB, clinical risk index for babies.

Abnormal thyroid size is often found in disease states and therefore thyroid volume was thought to correlate with thyroid gland development and thyroid function [6]. Thyroid ultrasonography and radionuclide scanning are the imaging modalities of choice in the assessment of thyroid gland in infants and children [7]. Thyroid ultrasound is non-invasive and is superior to radionuclide scanning in the assessment of normally located thyroid glands. It provides good evaluation of thyroid structure, location, vascularity, and echogenicity but may be less accurate than radionuclide scanning depending on expertise in the diagnosis of ectopic thyroid tissue $[8,9]$.

Several studies in the past used ultrasound measurement of the thyroid gland to determine normal thyroid volume in infancy. The earliest study was dated in 1997 by Vade et al. [10], which found a mean thyroid volume of $0.47 \mathrm{~mL}$ (standard deviation, $\mathrm{SD} \pm 0.14$ ) in 68 term neonates whose gestational ages at birth were 37-41 weeks. In 1999, Tajtakova et al. [11] assessed 258 newborns (227 term and 31 preterm) and found a mean thyroid volume of $0.6 \mathrm{~mL}$ ( $\mathrm{SD} \pm 0.21$ ). In a Turkish population, Kurtoglu et al. [12] reported a mean thyroid volume of $0.4 \mathrm{~mL}$ (SD $\pm 0.05)$ in 100 preterm infants born at gestational age of 25-28 weeks compared to $0.72 \mathrm{~mL}(\mathrm{SD} \pm 0.05)$ in 100 term infants. The most recent study carried out by Freire et al. [13] in 2014 suggested a normal reference interval for thyroid volume of between 0.45 and $1.53 \mathrm{~mL}$ (mean 1.0) in 125 term neonates studied. The authors believe that thyroid volume for term infants found in previous studies cannot be comparable to premature infants because of various factors related to prematurity affecting normal thyroid development.
To the authors' knowledge, this is the second largest prospective study of thyroid volume measurement at 36 weeks' corrected gestational age (CGA) in extremely preterm infants born before 28 weeks' gestation. There have been no similar studies to date on preterm infants within a UK population. The aim of this study was to assess thyroid volume in extremely preterm infants born before 28 weeks' gestation and evaluated at 36 weeks' CGA compared to term infants' normative data in the literature.

\section{Subjects and Method}

Fifty-five extremely preterm infants (28 males) who were born before 28 weeks' gestation were recruited to the study from 5 tertiary neonatal units in the north west of the UK. All infants had ultrasound assessment of the thyroid gland at 36 weeks' CGA. The following were excluded: infants born to mothers with known thyroid disease, on antithyroid medications, or on amiodarone; infants with major congenital or chromosomal abnormalities known to affect thyroid function or brain development; and infants whose mothers died within 5 days of giving birth.

The thyroid gland was measured using a linear array transducer. The infant was positioned in a supine position, with a roll of towel placed underneath the infant's shoulder to allow the neck to be positioned slightly hyper-extended. A generous amount of coupling gel was applied to the transducer surface, which was placed midline on the neck of the infant. Images were obtained using high-frequency probes $(10-15 \mathrm{MHz})$ in both transverse and longitudinal plane. All thyroid gland scans and measurements were performed by a single trained observer.

The thyroid volume of each lobe (right and left) was calculated by the formula: depth $\times$ length $\times$ width $\times \pi / 6$. The total volume were calculated as the sum of the volume of the right and left lobes. The isthmus was not taken into account in the volume measurement. Means and SD of the errors were calculated.

We also prospectively measured thyroid stimulating hormone (TSH) and free thyroxine $\left(\mathrm{FT}_{4}\right)$ in all infants at the time of recruitment (within 5 days of birth), at days 14, 21, and 28, and at 36 weeks' CGA. These were measured by solid phase 2 site chemiluminescent immunometric assay using DPC Immulite 2000. The $\mathrm{TSH}, \mathrm{FT}_{4}$, and mean thyroid volume were determined at 36 weeks' gestation. Data are expressed as mean (SD) for continuous parametric outcomes, and as median and interquartile range (IQR) for non-parametric outcomes. The study was approved by the UK North West research ethics committee (Ref. No. 07/MRE08/37).

\section{Results}

Demographic data are shown in Table 1 . The median gestational age at birth was 26.2 weeks $( \pm 1.2)$ and the mean birth weight was $893.8 \mathrm{~g}( \pm 178.1)$. There were no differences in baseline characteristics between eligible infants recruited between centres. 


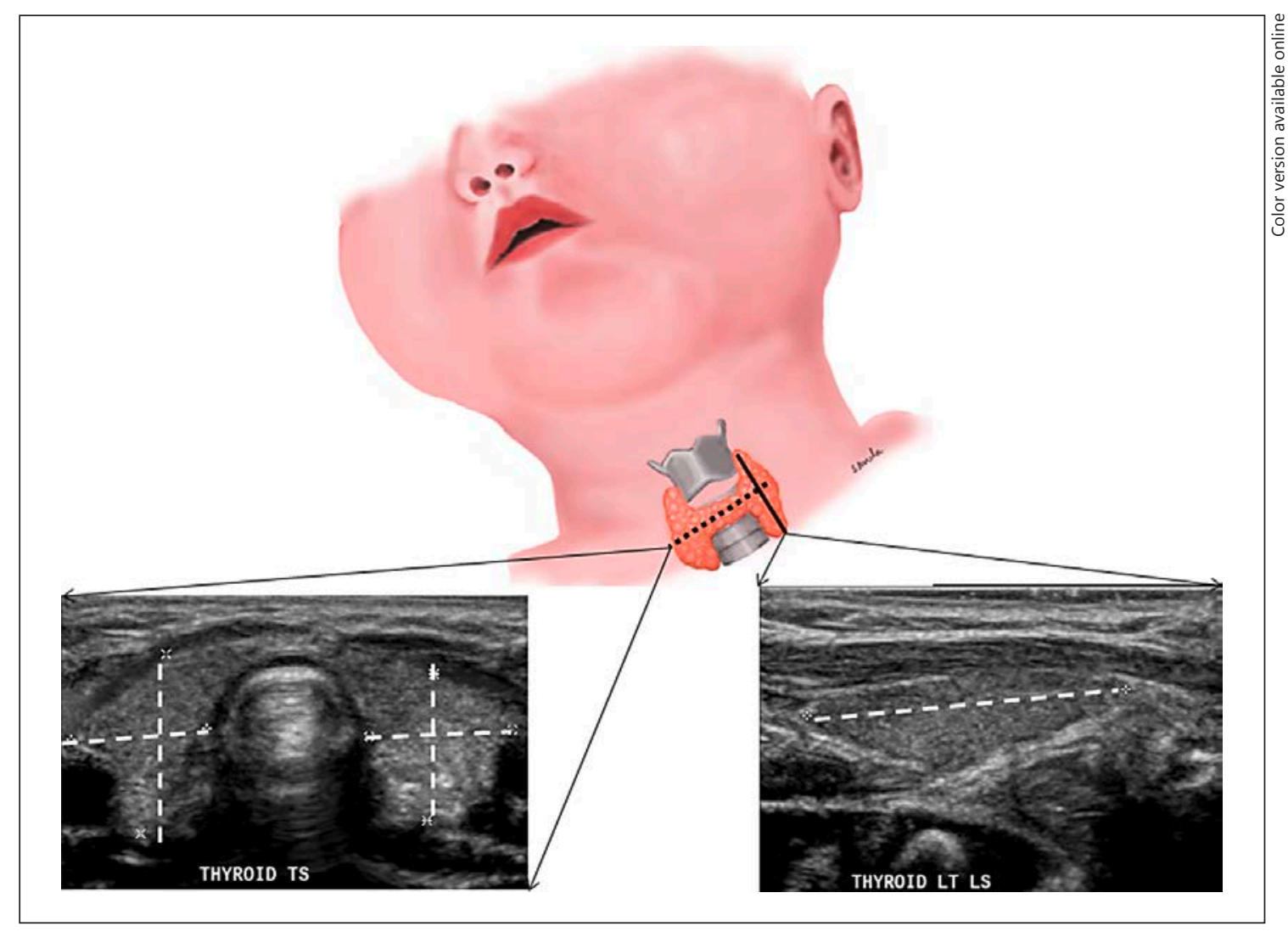

Fig. 1. Measurement of thyroid gland volume. Transverse and \pm longitudinal sections obtained to assess the depth, width, and length of the individual thyroid lobes.

The thyroid gland was easily identified at the lower part of the neck with the appearance of a homogenous bi-lobed structure with higher echogenicity compared to the neck muscles (Fig. 1). The thyroid lobes are bordered laterally by the common carotid arteries and the internal jugular veins, and medially by the trachea. Anterior to the lobe are the anterior muscles of the neck and posterior to the thyroid are the longus colli muscles. The oesophagus was seen with an echogenic mucosa and the trachea is visible laterally. In the neonate, the thyroid lobes appeared ovoid in transverse sections in contrast to the triangular shape noted in older infants. The mean thyroid volume was measured at $0.57 \mathrm{~mL}(\mathrm{SD} \pm 0.18)$. Intra-observer variation was calculated to be $6 \%$ (SD \pm 0.35 ), which was based on 10 measurements taken by a single person on separate occasions in the same patient. Colloid follicles appearing as small cystic (anechoic) structures of 1-3 mm were occasionally seen within the parenchyma and sometimes contained echogenic foci, a typical finding due to the presence of microcrystals [14].

Thyroid Gland Volume in Extremely Preterm Infants
Table 2. Comparison of thyroid function, auxology, clinical data, and thyroid volume at 36 weeks $(N=55)$

Head circumference at 36 weeks, $\mathrm{cm}$ $30.61(2.18)$

Weight at 36 weeks, $\mathrm{kg}$ $2.0(0.40)$

Week $36 \mathrm{TSH}, \mathrm{mU} / \mathrm{L}$

Median $\quad 3.60$

IQR

$2.10-4.70$

Week $36 \mathrm{FT}_{4}$, pmol/L

$16.76(3.34)$

Week $36 \mathrm{FT}_{3}$, pmol/L

$4.14(1.48)$

Thyroid volume at 36 weeks, $\mathrm{mL}$

$0.57(0.18)$

Duration of mechanical ventilation at 36 weeks, days

Median $\quad 21.0$

IQR $\quad 8-42$

Duration of TPN at 36 weeks, days Median

IQR

14.5

$11-21$

Chronic lung disease at 36 weeks, $n(\%)$

$39(70)$

Data are expressed as mean (SD) for continuous parametric outcomes and median and interquartile ranges (IQR) for nonparametric outcomes. TPN, total parenteral nutrition. 
Table 3. Current studies of reported mean thyroid volumes

\begin{tabular}{llll}
\hline Authors & Country & Thyroid volume, $\mathrm{mL}$ & Gestational age at birth \\
\hline Ng et al. (current study) & UK & 0.57 (mean) $n=55$ & extremely preterm \\
Perry et al. [8] & UK & 1.6 (mean) $n=100$ & term \\
Kurtoglu et al. [12] & Turkey & 1.26 (mean) $n=100$ & term \\
Kurtoglu et al. [12] & Turkey & 0.40 (mean) $n=100$ & extremely preterm \\
Klingmuller et al. [17] & Germany & 1.1 (mean) $n=?$ & not described \\
Glinoer et al. [20] & Belgium & 1.05 (mean) $n=180$ & term \\
Freira et al. [13] & Brazil & 1.0 (mean) $n=125$ & term \\
Vade et al. [10] & USA & 0.9 (mean) $n=68$ & term \\
Chanoine et al. [19] & Belgium & 0.84 (mean) $n=85$ & term \\
Liesenkötter et al. [24] & Germany & 0.7 (mean) $n=38$ (received iodine) & term \\
Yao et al. [15] & & 1.5 (mean) $n=70$ (control group) & term \\
Böhles et al. [18] & China & 0.64 (mean) $n=85$ & 227 term, 31 preterm \\
Tajtakova et al. [11] & Germany & 0.61 (median) $n=65$ & 0.6 (mean) $n=258$ \\
\hline
\end{tabular}

There were no abnormalities noted such as ectopia or hemiagenesis. Auxology, thyroid function $\left(\mathrm{TSH}, \mathrm{FT}_{4}\right.$, $\mathrm{FT}_{3}$ ), and thyroid volume at 36 weeks' CGA are shown in Table 2. No significant associations were found between thyroid volume and thyroid function.

\section{Discussion}

Thyroid size may be a useful marker of thyroid status and ultrasonography establishes whether or not the thyroid tissue is present in its normal position or if there is athyreosis or hemiagenesis. Determination of the presence or absence of the thyroid and structure of the gland is important for suspected cases of goitre or congenital hypothyroidism. Thyroid ultrasonography remains the most accurate diagnostic modality for determining thyroid disorders in children and serum thyroglobulin has not been established as a reliable alternative [15]. The incidence of hyperthyrotropinaemia and probable thyroid dysfunction is high in babies born prematurely [16]. The thyroid volume of extremely premature infants found in our study was not similar to that reported by publications of term infants. Thus, it is important to consider the gestational age at birth when evaluating the thyroid size. Our study is the only one of its kind from the UK and we believe that the findings could be considered as normative data for this neonatal group in the UK. However, the interpretation of this technique remains difficult in a setting where there is a lack of normative data for preterm infants within a UK population.
In Scotland, term neonates were found to have a mean thyroid gland volume of $1.63 \mathrm{~mL}$ ( $\mathrm{SD} \pm 0.37$ ), which was higher than that in other published data (summarised in Table 3) [8]. In Germany, 2 studies were published in term newborns, Klingmuller et al. [17] reported a mean thyroid volume of $1.1 \mathrm{~mL}$ ( $\mathrm{SD} \pm 0.6$ ), while Böhles et al. [18] reported a median thyroid volume of $0.61 \mathrm{~mL}$. In Belgium, Chanoine et al. [19] reported a mean thyroid volume in term newborns of $0.84 \mathrm{~mL}(\mathrm{SD} \pm 0.38$ ), whilst Glinoer et al. [20] reported a mean thyroid volume of 1.05 $\mathrm{mL}$ (SD \pm 0.34$)$. Vade et al. [10] reported that in USA term euthyroid neonates had a thyroid gland volume ranging between 0.47 and $1.43 \mathrm{~mL}$. A recent Polish study by Mikołajczak et al. [21] reported a median thyroid volume of $0.7 \mathrm{~mL}$ assessed at 1 week of life in 148 term babies.

During pregnancy the maternal iodine supply may influence complex changes of maternal thyroid function, which may affect the neonatal thyroid gland [22]. In 1992, most European countries (with the exceptions of Switzerland, Austria, Great Britain, and most Scandinavian countries) were still affected by mild to moderate degrees of iodine deficiency [23]. This variation in iodine levels could reflect the maternal iodine status, which may affect thyroid volumes depending on the gestational age of the child. Table 4 shows the Global Iodine Nutrition Scorecard 2012, which found mean urine iodine excretion of $80 \mu \mathrm{g} / \mathrm{L}$ in the UK, which suggests deficiency of iodine intake. This may explain the relatively higher thyroid volume in our study of preterm infants and in the infants reported by Perry et al. [8]. 
Table 4. Global iodine nutrition variation

\begin{tabular}{llll}
\hline Country & $\begin{array}{l}\text { Global Iodine Nutrition } \\
\text { Scorecard 2012 }- \\
\text { median UIE, } \mu \mathrm{g} / \mathrm{L}^{\mathrm{a}}\end{array}$ & $\begin{array}{l}\text { Classification of iodine intake }- \\
\text { WHO global database on iodine } \\
\text { deficiency (survey year) }\end{array}$ & $\begin{array}{l}\text { Mean thyroid volume, } \\
\mathrm{mL}\end{array}$ \\
\hline $\mathrm{UK}$ & 80 & No data & 1.6 (UK - Scotland) \\
Turkey & 107 & Insufficient (1997-1999) & 0.94 \\
Belgium & 113 & Insufficient (1998) & 0.8 \\
Germany & 122 & Adequate (1999) & 0.6 \\
Czech Rep & 163 & Adequate $(2000)$ & 0.6 \\
Slovakia & 183 & Adequate $(2002)$ & 0.9 \\
USA & 215 & More than adequate (1988-1994) & 0.64 \\
China & 246 & More than adequate $(2002)$ & 1.0 \\
Brazil & 360 & Excessive (2000) &
\end{tabular}

UIE, urinary iodine excretion. ${ }^{a}$ UIE of less than $100 \mu \mathrm{g} / \mathrm{L}$ indicates deficient iodine intake.

It is known that mean values and upper limits appear to differ according to iodine intake and urinary iodine. Thus, in newborns of iodine-supplemented mothers, the upper limit of thyroid gland volume in the study cohort of newborns was lower than that in reported studies with $1.4 \mathrm{~mL}$ (Glinoer et al. [20]) and $1.6 \mathrm{~mL}$ (Liesenkötter [24]). Turkey has been long known as an area of mild to moderate iodine deficiency according to the figures obtained from previous epidemiological studies (Table 4). Kurtoglu et al. [25] reported that in Central Anatolia (Kayseri) of Turkey, the mean thyroid volume of term newborns was $1.26 \mathrm{~mL}(\mathrm{SD} \pm 0.36)$. After the national salt iodisation program, the same region of Kayseri reported that the mean thyroid volume was reduced to $0.99 \mathrm{~mL}$ ( $\mathrm{SD} \pm 0.79$ ). A subsequent study by the same group reported that the median values of urinary iodine in mothers and their babies on the 5th day after delivery were $30.20 \mathrm{~g} / \mathrm{L}$ (range 3.20-171.50) and 23.80 g/L (3.20-95.30), respectively, [25], indicating that Kayseri was still an area of moderate iodine deficiency.

This is the only study assessing extremely premature neonates in view of providing more insight into thyroid volume in this age group within a UK population and setting standards for thyroid function assessment in extremely premature infants. However, there are also other factors affecting thyroid gland volume measurements including geographic reasons related to iodine intake, ethnicity, and maternal factors [26]. Current normative studies to date have found different thyroid gland volumes, which underlines the importance of establishing a more accurate dataset of thyroid volumes within different populations.

Thyroid Gland Volume in Extremely Preterm Infants

In conclusion, thyroid volume at birth can vary from country to country due to variations in iodine intake as well as gestational age. Our study of extremely premature infants born in the UK before 28 weeks' gestation who had their thyroid volume measurement assessed at 36 weeks' CGA provide a reference data of $0.57 \mathrm{~mL}$ (SD \pm 0.18 ) in this age group compared to the reported Scottish data of a mean thyroid volume of $1.6 \mathrm{~mL}$ in term infants.

\section{Disclosure Statement}

All authors declare that they have no conflict of interest.

References

Eur Thyroid J 2018;7:21-26 DOI: $10.1159 / 000481857$
1 Olivieri A, Fazzini C, Medda E: Multiple factors influencing the incidence of congenital hypothyroidism detected by neonatal screening. Horm Res Paediatr 2015;83:86-93.

2 Ng SM, Wong SC, Isherwood DM, Smith CS, Didi M: Multivariate analysis on factors affecting suppression of thyroid-stimulating hormone in treated congenital hypothyroidism. Horm Res 2004;62:245-251.

3 Ng SM, Turner MA, Gamble C, Didi M, Victor S, Manning D, Settle P, Gupta R, Newland $\mathrm{P}$, Weindling AM: An explanatory randomised placebo controlled trial of levothyroxine supplementation for babies born $<28$ weeks' gestation: results of the TIPIT trial. Trials 2013;14:211.

4 Ng SM, Watson G, Turner MA, Newland P, Weindling AM: Do maternal factors influence neonatal thyroid status in the extreme premature infant? J Matern Fetal Neonatal Med 2015;28:1846-1849. 
5 Gietka-Czernel M, Debska M, Kretowicz P, Zgliczynski W, Oltarzewski M: Hyperthyroidism during pregnancy - the role of measuring maternal TSH receptor antibodies and foetal ultrasound monitoring. Endokrynol Pol 2014;65:259-268.

6 Cohen O, Pinhas-Hamiel O, Sivan E, Dolitski M, Lipitz S, Achiron R: Serial in utero ultrasonographic measurements of the fetal thyroid: a new complementary tool in the management of maternal hyperthyroidism in pregnancy. Prenat Diagn 2003;23:740-742.

7 Muir A, Daneman D, Daneman A, Ehrlich R: Thyroid scanning, ultrasound, and serum thyroglobulin in determining the origin of congenital hypothyroidism. Am J Dis Child 1988;142:214-216.

8 Perry RJ, Hollman AS, Wood AM, Donaldson MD: Ultrasound of the thyroid gland in the newborn: normative data. Arch Dis Child Fetal Neonatal Ed 2002;87:F209-F211.

9 Lucas-Herald A, Jones J, Attaie M, Maroo S, Neumann D, Bradley T, Hermanns P, Pohlenz J, Donaldson M: Diagnostic and predictive value of ultrasound and isotope thyroid scanning, alone and in combination, in infants referred with thyroid-stimulating hormone elevation on newborn screening. J Pediatr 2014; 164:846-854

10 Vade A, Gottschalk ME, Yetter EM, Subbaiah P: Sonographic measurements of the neonatal thyroid gland. J Ultrasound Med 1997;16: 395-399.

11 Tajtakova M, Capova J, Bires J, Sebokova E, Petrovicova J: Thyroid volume, urinary and milk iodine in mothers after delivery and their newborns in iodine-replete country. Endocr Regul 1999;33:9-15.
12 Kurtoglu S, Ozturk MA, Koklu E, Gunes T, Akcakus M, Yikilmaz A, Buyukkayhan D, Hatipoglu N: Thyroid volumes in newborns of different gestational ages: normative data. Arch Dis Child Fetal Neonatal Ed 2008; 93:F171.

13 Freire R, Monte O, Tomimori EK, Catarino RM, Sterza T, Rocha T, Pereira KC, Mattos HS Jr, Fagundes LB, Liberato MM et al: Sonographic evaluation of the thyroid size in neonates. J Clin Ultrasound 2014, DOI: 10.1002/ jcu.22244.

14 Babcock DS: Thyroid disease in the pediatric patient: emphasizing imaging with sonography. Pediatr Radiol 2006;36:299-308; quiz 372-293.

15 Yao D, He X, Yang RL, Jiang GP, Xu YH, Zou CC, Zhao ZY: Sonographic measurement of thyroid volumes in healthy Chinese infants aged 0 to 12 months. J Ultrasound Med 2011; 30:895-898.

$16 \mathrm{Ng}$ SM: Hypothyroxinemia of prematurity: cause, diagnosis and management. Exp Rev Endocrinol Metab 2008;3:453-462.

17 Klingmuller V, Fiedler C, Otten A: Characteristics of thyroid sonography in infants and children (in German). Radiologe 1992;32: 320-326.

18 Böhles $\mathrm{H}$, Aschenbrenner $\mathrm{M}$, Roth $\mathrm{M}$, von Loewenich V, Ball F, Usadel KH: Development of thyroid gland volume during the first 3 months of life in breast-fed versus iodinesupplemented and iodine-free formula-fed infants. Clin Investig 1993;71:13-20.
19 Chanoine JP, Toppet V, Lagasse R, Spehl M, Delange F: Determination of thyroid volume by ultrasound from the neonatal period to late adolescence. Eur J Pediatr 1991;150:395-399.

20 Glinoer D, De Nayer P, Delange F, Lemone M, Toppet V, Spehl M, Grun JP, Kinthaert J, Lejeune B: A randomized trial for the treatment of mild iodine deficiency during pregnancy: maternal and neonatal effects. J Clin Endocrinol Metab 1995;80:258-269.

21 Mikołajczak A, Borszewska-Kornacka MK, Bokiniec R: Sonographic reference ranges for the thyroid gland in euthyroid term newborns. Am J Perinatol 2015;32:1257-1262.

22 Mahajan SD, Aalinkeel R, Singh S, Shah P, Gupta N, Kochupillai N: Thyroid hormone dysregulation in intrauterine growth retardation associated with maternal malnutrition and/or anemia. Horm Metab Res 2005;37: 633-640.

23 Delange F: Iodine deficiency in Europe and its consequences: an update. Eur J Nucl Med Mol Imaging 2002;29(suppl 2):S404-416.

24 Liesenkötter KP, Gopel W, Bogner U, Stach B, Gruters A: Earliest prevention of endemic goiter by iodine supplementation during pregnancy. Eur J Endocrinol 1996;134:443448 .

25 Kurtoglu S, Akcakus M, Kocaoglu C, Gunes T, Budak N, Atabek ME, Karakucuk I, Delange F: Iodine status remains critical in mother and infant in Central Anatolia (Kayseri) of Turkey. Eur J Nutr 2004;43:297-303.

26 Klein RZ, Carlton EL, Faix JD, Frank JE, Hermos RJ, Mullaney D, Nelson JC, Rojas DA, Mitchell ML: Thyroid function in very low birth weight infants. Clin Endocrinol (Oxf) 1997;47:411-417. 